\title{
Optimal Timing and Capacity Choice with Taxes and Subsidies Under Uncertainty*
}

\author{
Alcino Azevedo ${ }^{\dagger}$, Paulo J. Pereira ${ }^{\ddagger}$, Artur Rodrigues ${ }^{\S \dagger}$ \\ ${ }^{\dagger}$ Aston Business School, Aston University, Birmingham, UK \\ ${ }^{\ddagger}$ CEF.UP and Faculdade de Economia, Universidade do Porto, Porto, Portugal

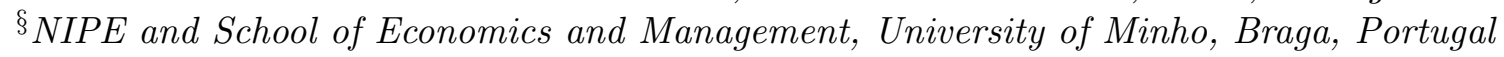

July 2020

\begin{abstract}
We develop a real options model that examines the effect of government's subsidies and taxation policy on the timing and size of investments. We find that a higher depreciation rate or subsidy, or a lower tax rate, accelerates investments. The effect of subsidies on the investment size depends on whether the subsidy is fixed or variable: a fixed subsidy induces smaller size investments, whereas a variable subsidy encourages larger size investments. The tax and depreciation rates do not affect the size of the investment. For revenue-neutral incentive packages, the effect of changes in the above variables on the investment timing and size is not necessarily monotonic and it depends on the instrument of the tax-subsidy policy that is used to keep the new policy revenue neutral. There are also economic contexts in which an increase in the tax rate can accelerate investments of a larger scale.
\end{abstract}

Keywords: Capacity Choice; Investment Subsidy; Real Options; Taxation Policy; Uncertainty.

\footnotetext{
${ }^{*}$ We thank the anonymous referees, Stefan Kupfer and participants at the 2017 Annual International Real Options Conference. Paulo J. Pereira and Artur Rodrigues acknowledge that this research has been financed by national funds of the FCT Portuguese Foundation for Science and Technology within the projects UIDB/04105/2020 and UIDB/03182/2020, respectively.

${ }^{\dagger}$ Corresponding author. E-mail address: a.azevedo@aston.ac.uk
} 


\section{Introduction}

Theoretical models describing the effect of tax incentives on investment go back to the neoclassical investment theory and were initially developed by Jorgenson (1963). The rationale of those models is that investment increases because the cost of capital decreases with a lower tax rate. The use of subsidies to promote investments is also popular, particularly for renewal energy (Yang et al., 2018; Huang et al., 2019), research and development (Busom, 2000; Huang et al., 2019), and foreign direct investments (FDI) (Haufler and Wooton, 1999; Bjorvatn and Eckel, 2006; Tian, 2018). Governments often stimulate investments relying on tax-subsidy packages, combining a subsidy to investment with taxes on profits "taking with one hand and giving with the other" (Hansson and Stuart, 1989, p. 549). There are cases where these packages are designed to be revenue-neutral for the government, as it is the case of the renewal energy feed-in-tariffs support schemes (Abrell et al., 2019).

There is a vast empirical literature studying the effect of the taxation policy on investment that is mostly consistent with the neoclassical theory (Hassett and Hubbard, 2002). For instance, Zee et al. (2002) and Klemm (2010) show that the tax rate is among the most important factors affecting investments, and Djankov et al. (2010) and Klemm and Van Parys (2012) conclude that reducing the tax rate is an effective tool to stimulate FDI, although Sorbe and Johansson (2017) find that the investments of tax planning multinational firms are less sensitive to the tax rate. The distortionary effects of taxation could be mitigated using investment tax incentives, for example extending investment expensing or a negative tax (a subsidy) on investment (Judd, 1997). The evidence that these incentives are capable of mitigating the effects of taxes is not clear (Hassett and Hubbard, 2002; Dimos and Pugh, 2016). In the US, the bonus depreciation policy has been shown to have a significant positive effect on investment (House and Shapiro, 2008), while the 2005 Domestic Production Activities Deduction, a revenue-neutral tax reform which combined lower corporate tax rates and faster accelerated depreciation, had a modest impact on corporate investment (Ohrn, 2018).

R\&D subsidies are regularly used by governments to promote innovation. In surveys of empirical evidence, David et al. (2000) and Becker (2015) show a shift to the support of positive effects of R\&D subsidies, and fewer evidence of a crowd-out effect of private R\&D investment. The relationship between $R \& D$ subsidies and private investment is not always linear, and can ex- 
hibit an inverted U-shape, changing sign after a given threshold (Guellec and Van Pottelsberghe De La Potterie, 2003; Görg and Strobl, 2007).

In this paper, we study the simultaneous effect of taxes and subsidies on both the timing and the size (capacity) of the investment, considering the tax and assets depreciation rates, and fixed and variable subsides, a unique contribution within the real option theory. The use of real options framework enables us to deal appropriately with the valuation of flexibility, considering the investment irresistibility and uncertainty (Dixit and Pindyck, 1994). We ignore, however, general equilibrium frameworks commonly used in macroeconomics (e.g. Fuest and Huber, 2000; Rotemberg, 2019; Straub and Werning, 2020).

Our work intersects with two branches of literature: one that studies the optimal investment timing and size under uncertainty neglecting taxes and subsidies ${ }^{1}$ and, another, which investigates the effect of taxes or subsidies on investment behavior under uncertainty. The former branch of the literature shows that although uncertainty delays investments it can encourage investments of a larger scale (Bar-Ilan and Strange, 1999; Dangl, 1999). Huisman and Kort (2015) extends this branch of literature to a duopoly and conclude that when the two firms invest sequentially the first-mover tends to overinvest in order to deter the entrance of the second-mover which invests later in a smaller scale. Boonman and Hagspiel (2013) study the effect of the use of different demand functions on the investment timing and size. Sarkar (2020) studies the uncertainty-investment relationship when a firm chooses both timing and size of investment, showing that it is not monotonic.

Few studies examine the simultaneous effect of taxes and subsidies on investment behavior, being among the exceptions the works of Pennings (2000) that shows that for irreversible investments a rise in the tax credit, if financed with an increase in the corporate tax rate, enhances investments, Agliardi (2001) that also considers the option to divest and concludes that the investment threshold increases with the tax rate and decreases with the size of the subsidy, and Sarkar (2012) which finds that the combination of the taxes and subsidies can be a sensible strategy to promote investments if the government's discount rate differs from that of the firm. Moreover, Yu et al. (2007) compare the use of an entry subsidy with the use of a tax rate reduction on FDI and find that the former policy is more economical and effective than the latter, and Tian (2018) evaluates how governments trade off these two policies, and conclude that their

\footnotetext{
${ }^{1}$ See Huberts et al. (2015) for a recent literature review.
} 
effectiveness in attracting FDI depends on the growth rate and market uncertainty. Pennings (2005) and Danielova and Sarkar (2011) show that the government can maximize its revenue by using a combination of tax reduction and investment subsidy.

The conventional wisdom on the effects of taxation is questioned by Alvarez and Koskela (2008) who show that, under progressive taxation, if the tax exemption is higher than the sunk cost, a rise in the tax rate does not necessarily defers investment. Gries et al. (2012) also find an identical tax paradox and highlight various tax regimes for which the post-tax investment threshold is not affected by the taxation policy. Overall, this literature concludes that a tax rate reduction is not necessarily good for investment, which contradicts the theoretical works following Jorgenson (1963).

Very few real options studies consider the effect of assets depreciation, with Adkins and Paxson (2013) and Sureth (2002) being notable exceptions. The former study shows that it has significant implications on investments, hastening investment, whereas the latter finds that a higher depreciation rate can defer investment.

We develop a theoretical model that examines the effect of a tax-subsidy policy on both the timing and the size of the investment considering various (taxes and subsidies) instruments. We show that a lower tax rate, a higher assets depreciation rate, or a higher subsidy hasten investments; fixed subsidies induce investments of a smaller scale; variable subsidies enhance investments of a larger scale; and the tax and the assets depreciation rates do not affect the size of the investment.

We also show that these conclusions may not hold when governments are financially constrained and changes in one of the policy instruments need to be offset by changes in another policy instrument. Specifically, we find that the effect of some of our model parameters on the timing and size of the investment is not always monotonic and depends on the instrument of the tax-subsidy policy that is adjusted to keep the policy changes revenue neutral. For instance, governments can enhance larger scale investments by increasing the tax rate as long as they use that additional tax revenue to grant a variable subsidy, or they can hasten investment if the additional tax revenues are used to increase the depreciation rate. Comparing our findings with those of Pennings (2000) and Wong (2012), we conclude that the consideration of the size of the investment and a more varied set of tax-subsidy instruments can lead to the existence of an ambiguous effect of the tax rate on the timing of the investment and makes the effect of 
the tax rate on the investment size dependent on how the tax revenue that results from the rise in the tax rate is used to enhance the investment. Additionally, our welfare analysis reveals that it is possible for the government to implement a welfare-maximizing policy by choosing the appropriate tax-subsidy package.

The remaining sections of the paper are organized as follows. Section 2 presents our real options models, considering the effect of assets depreciation and taxation policy with and without subsidies on the optimal investment timing and capacity choice, under an iso-elastic demand function. Section 3 studies the usage of neutral tax-subsidy packages. Section 4 provides a robustness check for the case of a linear demand function. Section 5 concludes the paper.

\section{The model}

\subsection{Without subsidy}

In this section, we develop a real options model which optimizes the size and timing of the investment. We follow Huisman and Kort (2015), although also considering the effect of taxation and assets depreciation policy. Let us assume that there is a new monopoly market where an isoelastic demand function holds and the output price is given by the following constant elasticity inverse demand function:

$$
P(t)=X(t) Q(t)^{-\gamma}
$$

where $Q(t)$ is the total market output, $\gamma \in(0,1)$ is the price elasticity parameter, and $X(t)$ is an exogenous shock which affects the output price and follows a geometric Brownian motion $(\mathrm{gBm})$ given by:

$$
d X(t)=\alpha X(t) d t+\sigma X(t) d w(t)
$$

where $X(t)>0, \alpha$ (with $\alpha<r$ ) is the risk-neutral expected drift, $r$ is the risk-free rate, $\sigma$ is the instantaneous volatility, $d w(t)$ is the increment of a Wiener process.

Let us also assume that the firm enters the market with a capacity $(Q)$ and the investment cost comprises two components: a fixed cost $\left(k_{0}\right)$ and a cost per output unit $\left(k_{1}\right)$. The total investment is therefore given by: $k_{0}+k_{1} Q$. Following Huisman and Kort (2015), we assume that after investing the firm operates at full capacity $(Q(t)=Q)$. 
The firm's objective function is given by:

$$
\begin{array}{r}
V(X)=\max _{T \geqslant 0, Q \geqslant 0} E\left[\int_{t=T}^{\infty}\left(Q X(t) Q^{-\gamma}(1-\tau)+\lambda\left(k_{0}+k_{1} Q\right) e^{-\lambda t} \tau\right) e^{-r t} d t\right. \\
\left.-\left(k_{0}+k_{1} Q\right) e^{-r T} \mid X(0)=X\right]
\end{array}
$$

where $\tau$ is the corporate tax rate, $T$ is the optimal time to invest, $Q$ is the optimal entry capacity level, and $\lambda\left(k_{0}+k_{1} Q\right) \tau$ is the continuous depreciation tax shield value. For the sake of simplicity, we assume a declining balance depreciation at the rate of $\lambda$ as in Adkins and Paxson (2013).

The solution for Equation (3) is attained in two steps (see Huisman and Kort, 2015). In a first step, we select the optimal capacity $\left(Q^{*}(X)\right)$ for a given $X(t)$, through:

$$
\max _{Q \geqslant 0} E\left[\int_{t=0}^{\infty}\left(Q X(t) Q^{-\gamma}(1-\tau)+\lambda\left(k_{0}+k_{1} Q\right) e^{-\lambda t} \tau\right) e^{-r t} d t-\left(k_{0}+k_{1} Q\right) \mid X(0)=X\right]
$$

which yields:

$$
Q^{*}(X)=\left(\frac{(1-\gamma)(1-\tau) X}{(r-\alpha) k_{1}} \frac{r+\lambda}{r+\lambda(1-\tau)}\right)^{\frac{1}{\gamma}}
$$

In a second step, we replace $Q$ in equation (3) by equation (5) and obtain the optimal investment threshold $\left(X^{*}\right)$, given by:

$$
\max _{X^{*}}\left[\left(\frac{Q^{*}\left(X^{*}\right) X^{*} Q^{*}\left(X^{*}\right)^{-\gamma}(1-\tau)}{r-\alpha}-\frac{r+\lambda(1-\tau)}{r+\lambda}\left(k_{0}+k_{1} Q\left(X^{*}\right)\right)\right)\left(\frac{X}{X^{*}}\right)^{\beta_{1}}\right]
$$

Proposition 1. In a market where a constant elasticity demand function $\left(P=X Q^{-\gamma}\right)$ holds, a firm with a monopoly position over the decision to invest in a project whose cost comprises a fixed component $\left(k_{0}\right)$ and a variable component - per output unit of the entry capacity level $\left(k_{1} Q\right)$, invests at the following optimal threshold:

$$
X^{*}=\left(\frac{\beta_{1}(1-\gamma) k_{0}}{\left(\beta_{1} \gamma-1\right) k_{1}}\right)^{\gamma} \frac{r-\alpha}{(1-\gamma)(1-\tau)} \frac{r+\lambda(1-\tau)}{r+\lambda} k_{1}
$$

with capacity:

$$
Q^{*} \equiv Q^{*}\left(X^{*}\right)=\frac{\beta_{1}(1-\gamma) k_{0}}{\left(\beta_{1} \gamma-1\right) k_{1}}
$$

where:

$$
\beta_{1}=\frac{1}{2}-\frac{\alpha}{\sigma^{2}}+\sqrt{\left(-\frac{1}{2}+\frac{\alpha}{\sigma^{2}}\right)^{2}+\frac{2 r}{\sigma^{2}}}
$$


with $\beta_{1} \gamma>1$, otherwise the firm would postpone investment forever (see Dixit and Pindyck, 1994) and $k_{0}>0$, otherwise the firm would invest immediately (see Huisman and Kort, 2015).

To perform a comparative statics of the tax policy instruments and uncertainty, we differentiate $X^{*}$ and $Q^{*}$ with respect to both the tax rate $(\tau)$ and the depreciation rate $(\lambda)$, which yields:

$$
\begin{aligned}
& \frac{\partial X^{*}}{\partial \tau}=\left(\frac{\beta_{1}(1-\gamma) k_{0}}{\left(\beta_{1} \gamma-1\right) k_{1}}\right)^{\gamma} \frac{r-\alpha}{(1-\gamma)(1-\tau)^{2}} \frac{r}{r+\lambda} k_{1}>0 \\
& \frac{\partial Q^{*}}{\partial \tau}=0 \\
& \frac{\partial X^{*}}{\partial \lambda}=-\left(\frac{\beta_{1}(1-\gamma) k_{0}}{\left(\beta_{1} \gamma-1\right) k_{1}}\right)^{\gamma} \frac{r-\alpha}{(1-\gamma)(1-\tau)} \frac{r \tau}{(r+\lambda)^{2}} k_{1}<0 \\
& \frac{\partial Q^{*}}{\partial \lambda}=0
\end{aligned}
$$

In Corollary 1, we summarize our findings for the effect of a tax policy which considers both a tax rate and an assets depreciation rate.

Corollary 1. For a firm with the monopoly over the decision to invest in a market where an iso-elastic demand function holds, a higher tax rate and a lower depreciation rate deter investment $\left(\partial X^{*} / \partial \tau>0, \partial X^{*} / \partial \lambda<0\right)$ and have no effect on the investment size/capacity $\left(\partial Q^{*} / \partial \tau=\partial Q^{*} / \partial \lambda=0\right)$.

From equations (10) and (12), it is possible to conclude that the sensitivity of the investment threshold to both $\tau$ and $\lambda$ decreases with the level of $\lambda$ and in the limit as $\lambda \rightarrow \infty$ becomes null.

Our results show that changes in the taxation policy can hasten or delay investments but have no effect the optimal capacity choice. The signs for the effect of the uncertainty on $X^{*}$ and $Q^{*}$ are the same as those of Huisman and Kort (2015):

$$
\begin{aligned}
\frac{\partial X^{*}}{\partial \sigma} & =\frac{\partial X^{*}}{\partial \beta_{1}} \frac{\partial \beta_{1}}{\partial \sigma}=-\left(\left(\frac{\beta_{1}(1-\gamma) k_{0}}{\left(\beta_{1} \gamma-1\right) k_{1}}\right)^{\gamma-1} \frac{\gamma}{\left(\beta_{1} \gamma-1\right)^{2}} \frac{r-\alpha}{1-\tau} \frac{r+\lambda(1-\tau)}{r+\lambda} k_{0}\right) \frac{\partial \beta_{1}}{\partial \sigma}>0 \\
\frac{\partial Q^{*}}{\partial \sigma} & =\frac{\partial Q^{*}}{\partial \beta_{1}} \frac{\partial \beta_{1}}{\partial \sigma}=-\left(\frac{(1-\gamma) k_{0}}{\left(\beta_{1} \gamma-1\right)^{2} k_{1}}\right) \frac{\partial \beta_{1}}{\partial \sigma}>0
\end{aligned}
$$

where $\partial \beta_{1} / \partial \sigma<0$ (Dixit and Pindyck, 1994).

Corollary 2. For a firm with the monopoly over the decision to invest in a market where an iso-elastic demand function holds, a higher uncertainty deters investments $\left(\partial X^{*} / \partial \sigma>0\right)$ but 
leads to investments with a larger capacity $\left(\partial Q^{*} / \partial \sigma>0\right)$.

The magnitude of the delay in the investment that results from higher uncertainty depends on the tax and assets depreciation rates (Equations (14) and (15)). Additionally, the delay increases with the tax rate $\left(\partial^{2} X^{*} / \partial \sigma \partial \tau>0\right)$ and decreases with the assets depreciation rate $\left(\partial^{2} X^{*} / \partial \sigma \partial \lambda<0\right)$, and the effect of uncertainty on the capacity choice is independent of both rates $\left(\partial^{2} Q^{*} / \partial \sigma \partial \tau=\partial^{2} Q^{*} / \partial \sigma \partial \lambda=0\right)$.

\section{$2.2 \quad$ With subsidy}

Let us now study the effect of government subsidies on firms' investment behavior, considering a fixed subsidy $\left(s_{0}\right)$ and a subsidy that varies with the size of the investment $\left(s_{1}\right)$. Notice that if we add a government subsidy to the modeling setting of the previous subsection, the subsidy should be discounted from the investment cost $\left(I_{s}\right)$. Therefore:

$$
I_{s}=\left(k_{0}-s_{0}\right)+\left(k_{1}-s_{1}\right) Q
$$

We obtain a solution for the optimization of the investment problem by replacing in the derivations of the previous subsection $k_{0}$ and $k_{1}$ by $k_{0}-s_{0}$ and $k_{1}-s_{1}$, respectively. Differentiating $X^{*}$ and $Q^{*}$ with respect to $s_{0}$ and $s_{1}$ yields:

$$
\begin{aligned}
\frac{\partial X^{*}}{\partial s_{0}} & =-\left(\frac{\beta_{1}(1-\gamma)\left(k_{0}-s_{0}\right)}{\left(\beta_{1} \gamma-1\right)\left(k_{1}-s_{1}\right)}\right)^{\gamma-1} \frac{\beta_{1} \gamma}{\beta_{1} \gamma-1} \frac{r-\alpha}{1-\tau} \frac{r+\lambda(1-\tau)}{r+\lambda}<0 \\
\frac{\partial Q^{*}}{\partial s_{0}} & =-\frac{\beta_{1}(1-\gamma)}{\left(\beta_{1} \gamma-1\right)\left(k_{1}-s_{1}\right)}<0 \\
\frac{\partial X^{*}}{\partial s_{1}} & =-\left(\frac{\beta_{1}(1-\gamma)\left(k_{0}-s_{0}\right)}{\left(\beta_{1} \gamma-1\right)\left(k_{1}-s_{1}\right)}\right)^{\gamma} \frac{r-\alpha}{1-\tau} \frac{r+\lambda(1-\tau)}{r+\lambda}<0 \\
\frac{\partial Q^{*}}{\partial s_{1}} & =\frac{\beta_{1}(1-\gamma)\left(k_{0}-s_{0}\right)}{\left(\beta_{1} \gamma-1\right)\left(k_{1}-s_{1}\right)^{2}}>0
\end{aligned}
$$

The effect of the fixed and the variable subsidy on the optimal timing and scale of the investment can be summarized as follows:

Corollary 3. For a firm with the monopoly over the decision to invest in a market where an iso-elastic demand function holds:

I. An increase in the fixed subsidy ( $\left.s_{0}\right)$ leads to earlier investments with a smaller capacity $\left(\partial X^{*} / \partial s_{0}<0, \partial Q^{*} / \partial s_{0}<0\right)$. 
II. An increase in the variable subsidy $\left(s_{1}\right)$ leads to earlier investments with a larger capacity $\left(\partial X^{*} / \partial s_{1}<0 \partial Q^{*} / \partial s_{1}>0\right)$.

Table 1 shows the sign of the relationship between each of the tax-subsidy package instruments and the optimal investment threshold and capacity choice, as well as the relationship between the uncertainty and the investment timing and capacity choice.

Table 1: Summary of comparative statics

\begin{tabular}{ccc}
\hline & $\partial X^{*}$ & $\partial Q^{*}$ \\
\hline$\partial \tau$ & + & 0 \\
$\partial \lambda$ & - & 0 \\
$\partial s_{0}$ & - & - \\
$\partial s_{1}$ & - & + \\
\hline$\partial \sigma$ & + & + \\
\hline
\end{tabular}

We conclude that a lower tax rate $(\tau)$, a higher depreciation rate $(\lambda)$, or a higher fixed or variable subsidy $\left(s_{0}\right.$ or $\left.s_{1}\right)$ hastens investments. An interesting result refers to the negative effect of a fixed subsidy on the capacity choice. The mechanism that explains such an impact is as follows: (i) $s_{0}$ has no direct effect on $Q^{*}(X)$, i.e., the optimal capacity, for any given $X$, is independent from $s_{0}$; (ii) there is a positive relation between $Q^{*}(X)$ and $X$, which means that a higher (lower) capacity is chosen when $\mathrm{X}$ is high (low); (iii) there is a negative effect of $s_{0}$ on $X^{*}$, which means that with a fixed subsidy the firm will optimally invest for a lower level of $X$; (iv) finally, joining (i), (ii) and (iii) we understand that the negative effect of $s_{0}$ on $Q^{*}\left(X^{*}\right)$ comes exclusively from the fact that the firm invests for a lower $X$ when $s_{0}$ is present.

Regarding the positive impact of $s_{1}$ on the capacity choice, the mechanism is now different because there is a positive relation between $Q^{*}(X)$ and $s_{1}$, i.e., a variable subsidy makes the firm invest in more scale. As the effects (ii) and (iii) previously presented remain valid herein, we conclude that the direct effect of $s_{1}$ on $Q^{*}(X)$ dominates these other effects explaining the positive impact of $s_{0}$ on $Q^{*}\left(X^{*}\right)$.

Additionally, the tax and the assets depreciation rates have no effect on the size of the investment. We also conclude that a higher uncertainty delays the investment but promotes investments of a larger scale. The delay due to uncertainty increases with the tax rate $\left(\partial^{2} X^{*} / \partial \sigma \partial \tau>\right.$ $0)$, and decreases with the assets depreciation rate and subsidies $\left(\partial^{2} X^{*} / \partial \sigma \partial \lambda<0, \partial^{2} X^{*} / \partial \sigma \partial s_{0}<\right.$ $\left.0, \partial^{2} X^{*} / \partial \sigma \partial s_{1}<0\right)$, and the effect of uncertainty on the capacity choice depends only of subsi- 
dies, increasing with the fixed subsidy and decreasing with the variable subsidy $\left(\partial^{2} Q^{*} / \partial \sigma \partial s_{0}>\right.$ $\left.0, \partial^{2} Q^{*} / \partial \sigma \partial s_{1}<0\right)$.

\section{$3 \quad$ Neutral tax-subsidy packages}

In the previous section, we provided a comparative statics analysis of the effect of the tax-subsidy policy instruments on the timing and scale of the investment. We did not considered, however, the impact of such policy on public budget. In fact, we assumed no budget constraints, and so the the effect of a change in one of the instruments did not require a compensation in another instrument, in order to mitigate the impact in public finances.

Governments, however, are financially constrained and they may want to stimulate private investment through the use of a tax-subsidy policy, conditional on the fact of being revenue neutral. For instance, the costs associated with fixed and variable subsidies would be compensated by a tax rate such that the present value of the all expected tax revenues is equal to the value of subsidies. This is a neutral tax-subsidy incentive package that can be used to promote investment. We refer to this type of neutral incentive as zero-cost package. ${ }^{2}$

This zero-cost tax-subsidy type of incentive was previously studied by Pennings (2000) and Wong (2012), using the real options approach. We depart, however, from their models by also taking into account the effect of assets depreciation on the investment timing and also by considering the effect of the incentive packages on optimal capacity choice.

The revenue obtained by a government when setting an investment incentive package is as follows:

$$
\begin{aligned}
R\left(X, \tau, \lambda, s_{0}, s_{1}\right) & =E\left[\int_{t=T}^{\infty}\left(Q^{*} P(X(t)) \tau-\lambda\left(k_{0}-s_{0}+\left(k_{1}-s_{1}\right) Q^{*}\right) e^{-\lambda t} \tau\right) e^{-r T} d t \mid X(0)=X\right] \\
& =\left(\left(\frac{X^{*} Q^{* 1-\gamma}}{r-\alpha}-\frac{\lambda}{r+\lambda}\left(k_{0}-s_{0}+\left(k_{1}-s_{1}\right) Q^{*}\right)\right) \tau-\left(s_{0}+s_{1} Q^{*}\right)\right)\left(\frac{X}{X^{*}}\right)^{\beta_{1}}
\end{aligned}
$$

where $T$ is the first time the state variable $X$ hits the threshold $X^{*}$. Hence, a zero-cost investment incentive package is defined as:

$$
R\left(X, \hat{\tau}, \hat{\lambda}, \hat{s_{0}}, \hat{s_{1}}\right)=0 .
$$

\footnotetext{
${ }^{2}$ The rationale underlying the use of this type of tax-subsidy package, where the government has no direct net revenue, can be related to indirect benefits such as promoting employment.
} 
This also means that any change in one element of the package needs to be offset by a change of another element so that to maintain the same zero net revenue.

However, one may argue that governments only exceptionally would be available to set a scheme where the subsidies offered for promoting investment precisely equals the corresponding tax revenues, waiving any positive impact of the investment on the public budget. In other words, governments would very much prefer to take use of a package that attain to the same objective (to promote private investment) ensuring, however, a positive revenue for the public entity. We refer to this type of neutral instrument as zero-incremental-cost package.

Accordingly, a zero-incremental-cost package can be defined as the set of adjustments needed in its components $\left(\tilde{\tau}, \tilde{\lambda}, \tilde{s_{0}}, \tilde{s_{1}}\right)$ such that no changes in the revenues of the government are produced. In other words, with the implementation of a zero-incremental-cost package the government secures the initial level of revenues, while being able to subsidize investment. Therefore, the conditions for a zero-incremental-cost package are:

$$
\begin{aligned}
& R\left(X, \tilde{\tau}, \tilde{\lambda}, \tilde{s_{0}}, \tilde{s_{1}}\right)-R\left(X, \tau, \lambda, s_{0}, s_{1}\right)=0 \\
& \text { s.t. } R\left(X, \tau, \lambda, s_{0}, s_{1}\right)>0
\end{aligned}
$$

\subsection{Effects neutral packages on timing and capacity choice}

Let us now extend the analysis of section 2.2 and study the effect of changes in the tax rate on the investment dynamics $\left(X^{*}\right.$ and $\left.Q^{*}\right)$, under the constraints of a zero-cost and a zero-incrementalcost type of package.

The effects of a zero-cost package By examining the effect of $\lambda, s_{0}$ and $s_{1}$ on $X^{*}$ and $Q^{*}$ under a zero-cost package (where the instruments of the tax-subsidy policy are used to make the package revenue neutral for the government, i.e. $R()=$.0 ) the following proposition can be presented:

Proposition 2. If governments want to adopt a zero-cost tax-subsidy policy to promote investment and decide to increase the tax rate, they are able to increase the amount of subsidies and the assets depreciation rate $-\partial \hat{\lambda} / \partial \hat{\tau}>0$ and $\partial \hat{s_{0}} / \partial \hat{\tau}>0, \partial \hat{s_{1}} / \partial \hat{\tau}>0$.

This finding considers the indirect effect of the change in government's revenue on the in- 
vestment timing and capacity choice. Notice that, from the last section, we conclude that an increase in the tax rate defers investment but has no effect on the capacity choice. Additionally, the instrument of the tax-subsidy policy that is adjusted to neutralize the effect of the tax rate change on the government revenue can have a different effect on the optimal investment timing and the capacity choice. Therefore, the total effect of a tax rate change on the investment timing and capacity choice, under a neutral tax-subsidy policy, should consider both the direct and the indirect effects through the instrument that is adjusted to make the policy change revenue neutral.

Combining the results presented in Section 2.2 (see Table 1) with those of Proposition 2, we see that the effects of a zero-cost package on $X^{*}$ and $Q^{*}$ are as follows:

$$
\begin{aligned}
& \frac{d \hat{X}^{*}}{d \hat{\tau}}=\underbrace{\frac{\partial \hat{X}^{*}}{\partial \hat{\tau}}}_{>0}+\underbrace{\frac{\partial \hat{X}^{*}}{\partial \hat{\lambda}}}_{<0} \underbrace{\frac{\partial \hat{\lambda}}{\partial \hat{\tau}}}_{>0}+\underbrace{\frac{\partial \hat{X}^{*}}{\partial \hat{s_{0}}} \underbrace{\frac{\partial \hat{s_{0}}}{\partial \hat{\tau}}}_{<0}}_{<0}+\underbrace{\frac{\partial \hat{X}^{*}}{\partial \hat{s_{1}}}}_{>0} \underbrace{\frac{\partial \hat{s_{1}}}{\partial \hat{\tau}}}_{<0} \gtreqless 0
\end{aligned}
$$

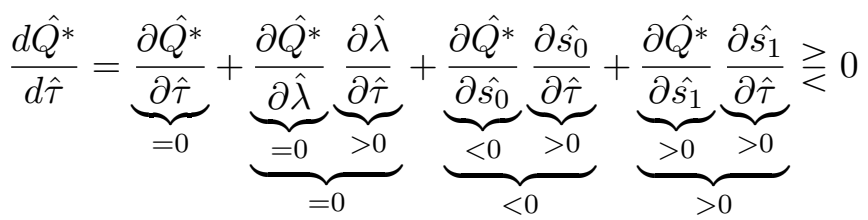

If any change in the tax rate is to be compensated by one of the other instruments of the tax-subsidy package, the corresponding effects on the optimal investment timing and capacity choice are according to the following corollary:

Corollary 4. A firm with the monopoly over the decision to invest in a market where an isoelastic demand function holds and facing a zero-cost tax-subsidy policy, if the tax rate increases, there is:

I. An ambiguous effect on the investment timing and no effect on capacity size if the effect of the tax rate on the government revenue is offset by an increase in the assets depreciation rate.

II. An ambiguous effect on the investment timing and a smaller capacity size if the effect of the tax rate on the government revenue is offset by an increase in the fixed subsidy.

III. An ambiguous effect on the investment timing and a greater capacity size if the effect of 
the tax rate increase on the government revenue is offset by an increase in the variable subsidy.

In all the above ambiguities, the final sign of the impact will depend on which effect happens to dominate, either the direct or the indirect effect, i.e. the effect of the instrument used to compensate the change in the tax rate.

The effects of a zero-incremental-cost package Consider now the zero-incremental-cost package where any change in one of the instruments need to be compensated by another instrument in such a way that the final level of revenues for the government remain unchanged, i.e., $\Delta R()=$.0 , with $R()>$.0 . Analyzing the individual effect of an increase in the tax rate on the other instruments, the following can be stated:

Proposition 3. If governments adopt a zero-incremental-cost tax-subsidy policy, in order to promote investment while maintaining a given positive revenue, an increase in the tax rate does not lead necessarily to an increase in the amount of subsidies and the assets depreciation rate $\partial \tilde{\lambda} / \partial \tilde{\tau} \gtreqless 0$ and $\partial \tilde{s_{0}} / \partial \tilde{\tau} \gtreqless 0, \partial \tilde{s_{1}} / \partial \tilde{\tau} \gtreqless 0$.

Differently from what we saw for the zero-cost package, in a zero-incremental-cost alternative (where a positive final revenue for the government needs to be secured) we do not find a clear relation between the instruments. For instance, a high tax rate, $\tau$, increases the level of revenues for the government which, however, will occur later, due to the deterrence effect of taxation on investment, and so suffering from a higher discount effect. Notice that this discount effect is not relevant in the zero-cost case, since no net revenues accrue to the government.

However it worth mentioning that, although ambiguous, as presented in Proposition 3, our simulations clearly show that, for reasonable sets of parameters, the relations presented in Proposition 2 for the zero-cost package tend to occur also for the zero-incremental-cost package. Only when the tax rate is extremely high the opposite effects occur.

Combining the results presented in Table 1 with those in Proposition 3 we see the following 
effects of a zero-incremental-cost package on the investment trigger and optimal capacity choice:

$$
\begin{aligned}
& \frac{d \tilde{X}^{*}}{d \tilde{\tau}}=\underbrace{\frac{\partial \tilde{X}^{*}}{\partial \tilde{\tau}}}_{>0}+\underbrace{\frac{\partial \tilde{X^{*}}}{\partial \tilde{\lambda}}}_{\gtrless 0} \underbrace{\frac{\partial \tilde{\lambda}}{\partial \tilde{\tau}}}_{\gtrless 0}+\underbrace{\frac{\partial \tilde{X}^{*}}{\partial \tilde{s_{0}}}}_{\gtrless 0} \underbrace{\frac{\partial \tilde{s_{0}}}{\partial \tilde{\tau}}}_{<0}+\underbrace{\frac{\partial \tilde{X}^{*}}{\partial \tilde{s_{1}}}}_{\gtrless 0} \underbrace{\frac{\partial \tilde{s_{1}}}{\partial \tilde{\tau}}}_{\gtrless 0} \underbrace{\frac{\gtrless}{\gtrless 0}}_{\gtrless 0} \\
& \frac{d \tilde{Q}^{*}}{d \tilde{\tau}}=\underbrace{\frac{\partial \tilde{Q}^{*}}{\partial \tilde{\tau}}}_{=0}+\underbrace{\frac{\partial \tilde{Q}^{*}}{\partial \tilde{\lambda}}}_{=0} \underbrace{\frac{\partial \tilde{\lambda}}{\partial \tilde{\tau}}}_{\gtrless 0}+\underbrace{\frac{\partial \tilde{Q}^{*}}{\partial \tilde{s_{0}}}}_{\gtrless 0} \underbrace{\frac{\partial \tilde{s_{0}}}{\partial \tilde{\tau}}}_{\gtrless 0}+\underbrace{\frac{\partial \tilde{Q}^{*}}{\partial \tilde{s}}}_{\gtrless 0} \underbrace{\frac{\partial \tilde{s_{1}}}{\partial \tilde{\tau}}}_{>0} \underbrace{\gtrless 0}_{\gtrless 0}
\end{aligned}
$$

When the changes in the tax rate are neutralized by one of the other instruments of the taxsubsidy package, the effects on the optimal investment timing and capacity choice are presented in the following corollary:

Corollary 5. A firm with the monopoly over the decision to invest in a market where an isoelastic demand function holds, and facing a zero-incremental-cost tax-subsidy policy, tax rate increases leads to:

I. An ambiguous effect on the investment timing and no effect on the capacity size if the effect of the tax rate on the government revenue is offset by an increase in the assets depreciation rate.

II. An ambiguous effect on the investment timing and the capacity size if the effect of the tax rate on the government revenue is offset by an increase in both types of subsidies.

All the results from the previous analyses are summarized in Table 2. They show that when government constraints are introduced and neutral packages are in place (either zero-cost or zero-incremental-cost), the clear relation appearing in the unrestricted context no longer exists. In fact, a tax rate increase used to compensate a higher depreciation rate or higher subsidies, may hasten or deter the investment, depending on the tax rate that it is initially due. Although the direct effect of an increase in the tax rate is the deterrence of the investment, we show that it is possible to speed-up the investment if the additional tax revenues is used to increase the depreciation rate or to concede a subsidy to the firm. 
Table 2: Summary of results: neutral tax-subsidy packages

\begin{tabular}{ccccccccc}
\hline & Unrestricted & \multicolumn{3}{c}{ Zero-cost package } & & \multicolumn{3}{c}{ Zero-incremental-cost package } \\
\cline { 3 - 4 } & & $\lambda$ & $s_{0}$ & $s_{1}$ & & $\lambda$ & $s_{0}$ & $s_{1}$ \\
\hline$d X^{*} / d \tau$ & + & \pm & \pm & \pm & & \pm & \pm & \pm \\
$d Q^{*} / d \tau$ & 0 & 0 & - & + & & 0 & \pm & \pm \\
\hline
\end{tabular}

Moreover, if governments want to induce investments of a larger scale, they should use the additional tax revenues to pay a variable subsidy, under a zero-cost package. For the zeroincremental-cost case, this can also be possible, but only for some particular sets of parameters. For both packages, the benefits of a higher depreciation tax rate reveals not to be an effective instrument for promoting investment scale. Comparing our results with those of Pennings (2000) and Wong (2012), we show the existence of an ambiguous effect of the tax rate on the investment timing, whereas the effect on investment size is dependent on which of the instruments of the tax-subsidy policy is used to neutralize the taxation effect.

Numerical example Using a numerical example we analyze the overall effects of the neutral tax-subsidy packages (both zero-cost and zero-incremental-cost) on the investment timing and scale. We compare the zero-cost and the zero-incremental-cost packages both with the unrestricted tax-subsidy package and with setting without government.

Figure 1 shows the effect of the tax rate on the timing and size of the investment. The effects of the unrestricted package correspond to those studied in the previous section. A higher tax rate deters investment (higher $X^{*}$ ) and has no effect on the investment scale $\left(Q^{*}\right)$. An increase in the tax rate allows the government to use the proceeds to increase the depreciation rate (Figure 1(a)), the fixed subsidy (Figure 1(d)) or the variable subsidy (Figure 1(g)). In Proposition 2 we already reported these results for the case of zero-cost package. Notice, however, that the positive relation we observe in this example for the zero-incremental-cost package is a result of our set of parameters. With different parameters, namely with an extremely high initial tax rate, a negative relation can occur. In any case, based on our simulations, we can assert that in the majority of the cases the positive relation revealed by Figures 1(a), 1(d) and 1(g) tend to prevail. Finally, notice that (i) decreasing the tax rate below a certain level implies negative depreciation rates and negative subsidies to compensate that effect, and (ii) there is a limiting tax rate above which it is no longer possible to compensate through the depreciation tax shields 


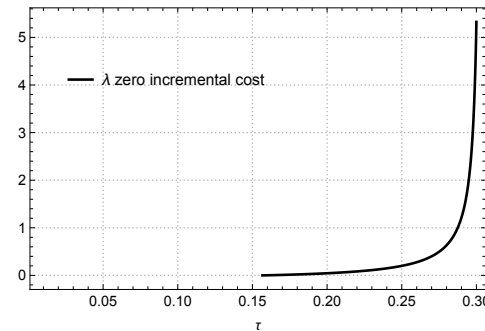

(a) $\lambda$ neutralizes $\tau$

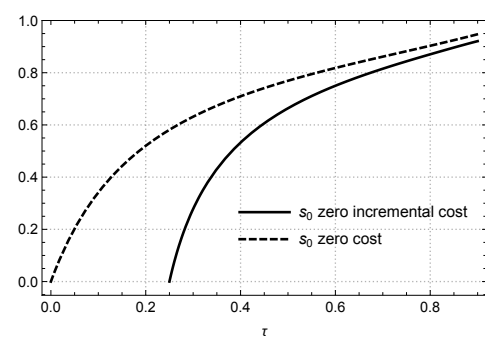

(d) $s_{0}$ neutralizes $\tau$

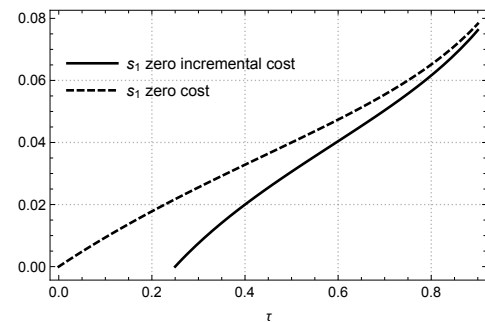

(g) $s_{1}$ neutralizes $\tau$

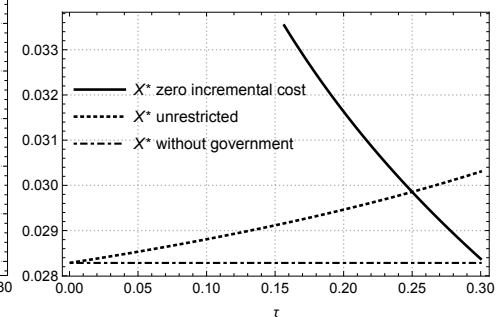

(b) $\lambda$ neutralizes $\tau-X^{*}$

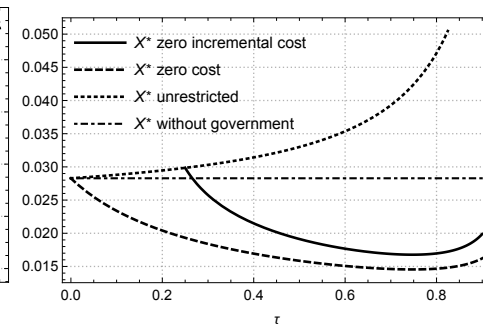

(e) $s_{0}$ neutralizes $\tau-X^{*}$

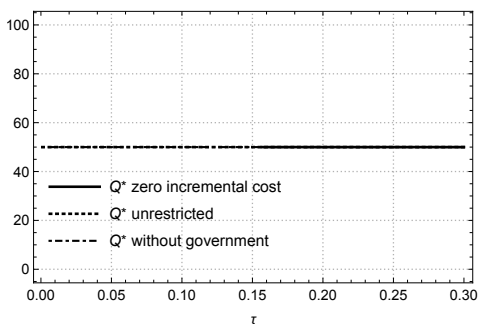

(c) $\lambda$ neutralizes $\tau-Q^{*}$

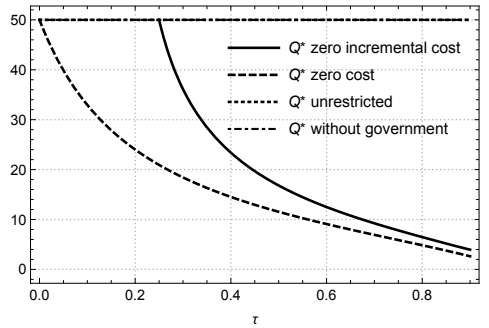

(f) $s_{0}$ neutralizes $\tau-Q^{*}$

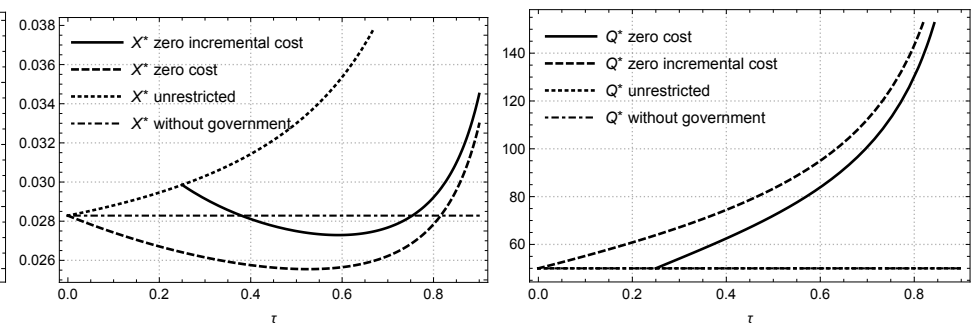

(h) $s_{1}$ neutralizes $\tau-X^{*}$

(i) $s_{1}$ neutralizes $\tau-Q^{*}$

$X=0.01, r=0.04, \alpha=0.02, \beta_{1}=2.5, \gamma=0.5, k_{0}=1, k_{1}=0.1, s_{0}=0, s_{1}=0, \tau=0.25, \lambda=0.2$.

Figure 1: The effects of the tax rate $(\tau)$ on the timing and the scale of the investment. 
(in our example, we see that the continuous depreciation rate goes to infinity as $\tau$ approaches a given threshold).

Figure 1(b) depicts a negative effect of tax rate on the trigger when compensated by the depreciation rate, showing that, for reasonable sets of parameters, it is possible to hasten investments without modifying its scale. ${ }^{3}$ For our set of parameters, a higher tax rate allows a higher depreciation rate that hastens investment. The direct effect of the tax rate is dominated by the indirect effect of the depreciation rate. Figures 1(e) and 1(h) show that, for both neutral packages, the effects of an increase of the tax rate on the investment timing is ambiguous, as stated in Corollaries 4 and 5. However, it is worth mentioning that, for reasonable levels of taxation, it is possible to hasten investments even when increasing the tax rate (up to a certain tax rate), as the positive effect of the subsidies (fixed or variable) more than compensate the direct negative effect of taxation. If the goal of the government is to speed up investment, this shows that it can be attained at high tax rates and subsidy amounts. Additionally, two possible effects on the capacity choice arise: (i) if the fixed subsidy is used to compensate the increase in $\tau$, we see a negative effect on the scale of the project (Figure 1(f)); whereas (ii) if we make use of a variable subsidy, a positive effect on capacity can be attained, i.e. it would be possible to invest sooner in a larger scale (Figure 1(i)).

In Section 2.1 we reported the well-known effect of uncertainty on the timing and scale of an investment. We saw that a higher uncertainty deters the implementation of the project but leads to investments with a larger capacity. Figure 2 extends the analysis to the case of the zero-incremental-cost tax-subsidy package, by considering different levels of uncertainty (higher uncertainty means a lower $\beta_{1}$ ). We find the same type of relation as before: both $X^{*}$ and $Q^{*}$ increase as $\beta_{1}$ decreases. However, these effects are much less significant when $s_{0}$ is the instrument used to compensate high levels of $\tau$ (see Figures 2(e) and 2(f)). Also Figure 2(i) reveal a smaller impact of uncertainty on the scale of the investment when $s_{1}$ is used and $\tau$ is low.

Furthermore, higher uncertainty (lower $\beta_{1}$ ) allows, in general, higher depreciation rates and higher subsidies (see Figures 2(a) (for $\tau>0.25$ ), 2(d) and 2(g)) for compensating a given tax rate. The reasoning for this effect relies on the well-known positive impact of volatility

\footnotetext{
${ }^{3}$ The threshold converges to the case without government because: $\lim _{\lambda \rightarrow \infty} X^{*}\left(s_{0}=0, s_{1}=0, \lambda, \tau\right)=X^{*}\left(s_{0}=\right.$ $\left.0, s_{1}=0, \lambda=0, \tau=0\right)$.
} 


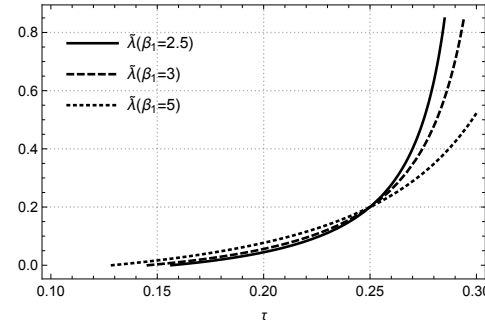

(a) $\lambda$ neutralizes $\tau$

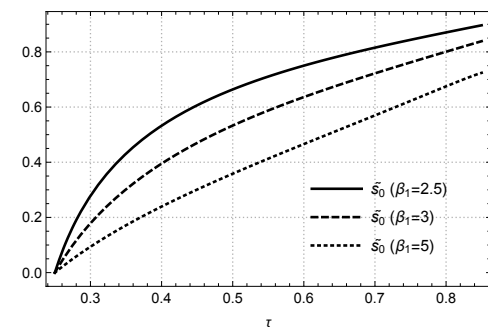

(d) $s_{0}$ neutralizes $\tau$

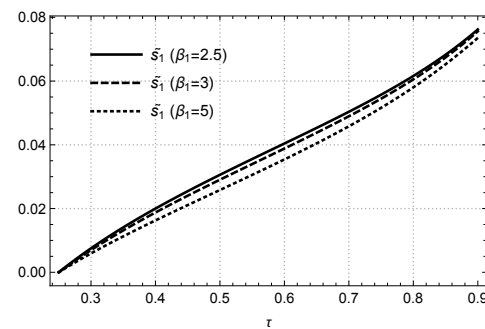

(g) $s_{1}$ neutralizes $\tau$

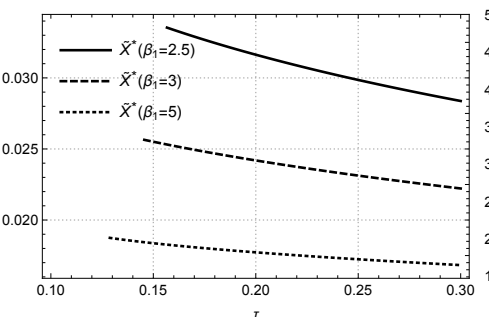

(b) $\lambda$ neutralizes $\tau-X^{*}$

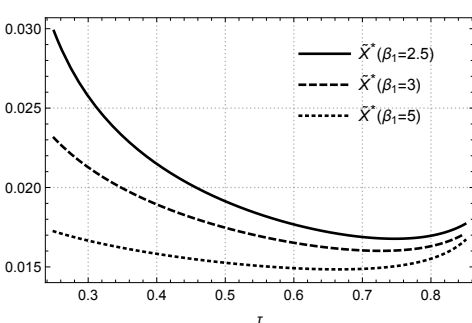

(e) $s_{0}$ neutralizes $\tau-X^{*}$

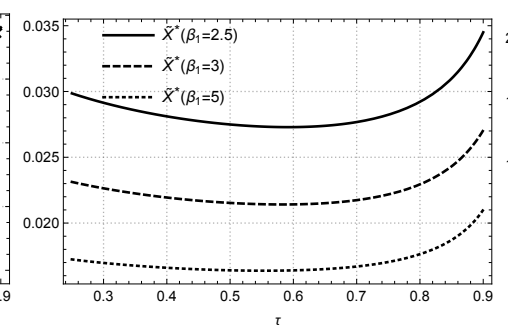

(h) $s_{1}$ neutralizes $\tau-X^{*}$

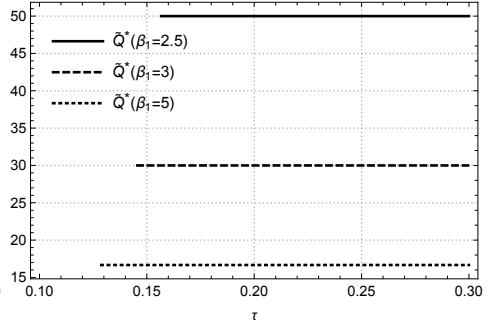

(c) $\lambda$ neutralizes $\tau-Q^{*}$

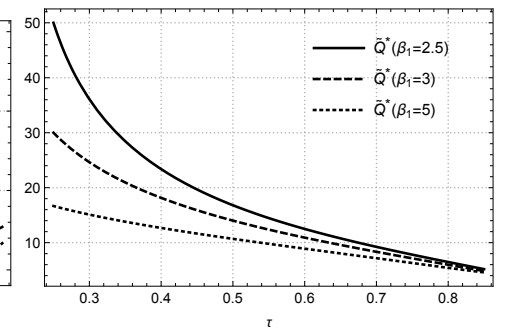

(f) $s_{0}$ neutralizes $\tau-Q^{*}$

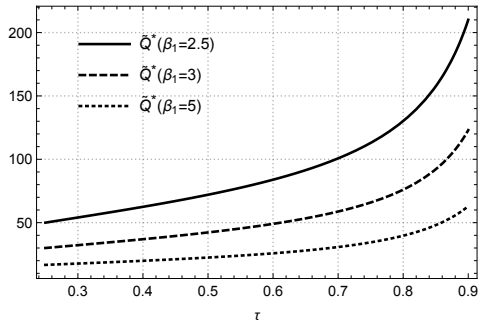

(i) $s_{1}$ neutralizes $\tau-Q^{*}$

$X=0.01, r=0.04, \alpha=0.02, \gamma=0.5, k_{0}=1, k_{1}=0.1, s_{0}=0, s_{1}=0, \tau=0.25, \lambda=0.2$.

Figure 2: Effects of the tax rate $\tau$ under different uncertainty levels for a zero-incremental-cost package.

on the option value, which, in our case, applies both for the firm value function, as well as for the government position, $R($.$) . Additionally, it is possible to show that this positive effect$ marginally increases for the government, and decreases for the firm, as the tax rate increases. In other words, as $\tau$ increases the government earns an increasingly larger fraction of the value arising from additional volatility. This is why larger tax rates allows the government to share more with the firm, namely through a higher depreciation rate or higher subsidies. However, an opposite effect occurs when the tax rate decreases. In fact, when $\tau$ is below the initial (pre-package) rate, the additional benefit of volatility is increasingly captured by the firm as $\tau$ decreases. In this context, the firm is now willing to share some of the value with the government resulting in lower depreciation rates when volatility is high (low $\beta_{1}$ ). 


\subsection{Welfare analysis}

From a social optimizer's perspective, the goal of the a government should be to maximize the total surplus, i.e. the sum of the producer surplus, the consumer surplus and the government revenue. It would be interesting to show if it is possible to maximize the welfare even under the constraints of neutral packages.

Given that the government revenues are expenses for the firm, a social optimizer maximizes the sum of the producer surplus and consumer surplus with the absence of taxes and subsidies.

Following Huisman and Kort (2015), the value of the producer surplus without taxes and subsidies is

$$
P S(X)=\left(\frac{X^{*}}{r-\alpha} Q^{* 1-\gamma}-\left(k_{0}+k_{1} Q^{*}\right)\right)\left(\frac{X}{X^{*}}\right)^{\beta_{1}}
$$

and the value of the consumer surplus is

$$
C S(X)=\frac{\gamma}{1-\gamma} \frac{X^{*}}{r-\alpha} Q^{* 1-\gamma}\left(\frac{X}{X^{*}}\right)^{\beta_{1}}
$$

where

$$
\begin{aligned}
X^{*} & =\left(\frac{\beta_{1}(1-\gamma)\left(k_{0}-s_{0}\right)}{\left(\beta_{1} \gamma-1\right)\left(k_{1}-s_{1}\right)}\right)^{\gamma} \frac{r-\alpha}{(1-\gamma)(1-\tau)} \frac{r+\lambda(1-\tau)}{r+\lambda}\left(k_{1}-s_{1}\right) \\
Q^{*} & =\frac{\beta_{1}(1-\gamma)\left(k_{0}-s_{0}\right)}{\left(\beta_{1} \gamma-1\right)\left(k_{1}-s_{1}\right)}
\end{aligned}
$$

are, respectively, the trigger and the optimal capacity choice in the presence of depreciation tax shields, fixed and variable subsidies.

Computing the total surplus, $T S(X)=P S(X)+C S(X)$, using equations (31) and (32), leads to:

$$
T S(X)=\left(\left(\frac{r+\lambda(1-\tau)}{(1-\gamma)(1-\tau)(r+\lambda)}-(1-\gamma) \frac{k_{1}}{k_{1}-s_{1}}\right) \frac{\beta_{1}}{\beta_{1} \gamma-1}\left(k_{0}-s_{0}\right)-k_{0}\right)\left(\frac{X}{X^{*}}\right)^{\beta_{1}}
$$

Notice that it is the firm who decides upon the timing and scale of investment (relying on equations (31) and (32)), while the government chooses the instruments of the neutral packages in order to maximize the total surplus, $T S(X)$. 
Figure 3 shows the effects on the welfare of the different instruments available in the neutral packages. We see that it is possible to increase the total surplus by increasing the tax rate while compensating it through the depreciation rate (Figure 3(a)). Interestingly, Figures 3(b) and $3(\mathrm{c})$ reveal that the zero-incremental-cost package tends be a more effective alternative than the zero-cost package, from a social optimizer perspective. Additionally, not only it is possible to improve social welfare, even beyond the "no-government" surplus, but also the government can implement a welfare-maximizing policy. In fact, Figure 3(b) depicts a maximum welfare that it is attained for reasonable levels of $\tau$, when the fixed subsidy is the instrument used. For the case of variable subsidy the maximum welfare only occurs for an unreasonably high tax rate.

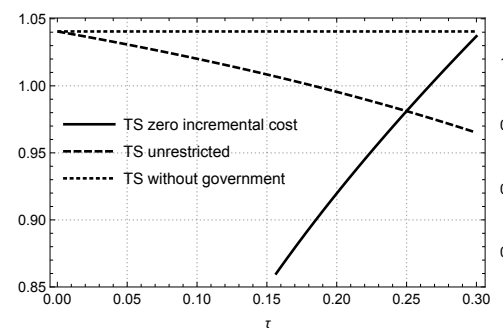

(a) $\lambda$ neutralizes $\tau$

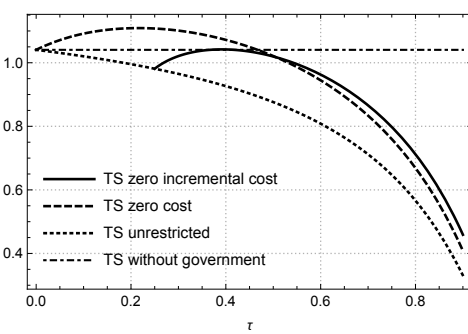

(b) $s_{0}$ neutralizes $\tau$

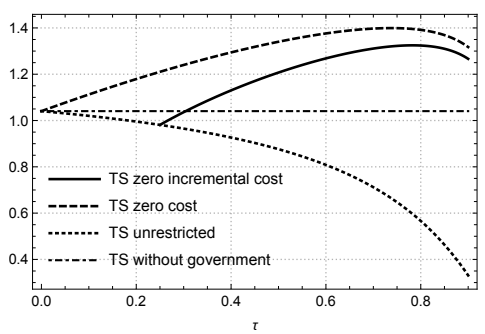

(c) $s_{1}$ neutralizes $\tau$ $X=0.01, r=0.04, \alpha=0.02, \beta_{1}=2.5, \gamma=0.5, k_{0}=1, k_{1}=0.1, s_{0}=0, s_{1}=0, \tau=0.25, \lambda=0.2$.

Figure 3: The effects of the tax rate $(\tau)$ on social welfare.

In Figure 4, we show the effect of uncertainty on the total surplus of the zero-incrementalcost package. Regardless of the instrument used to compensate $\tau$, a higher uncertainty (lower $\beta_{1}$ ) leads to a higher welfare, because of the optionality of the investment.

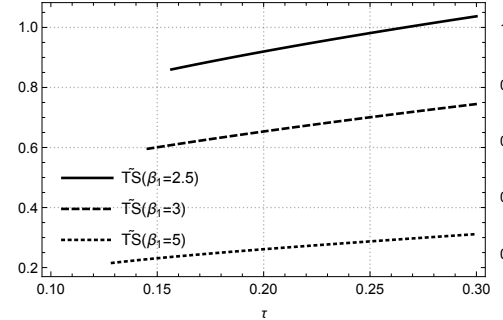

(a) $\lambda$ neutralizes $\tau$

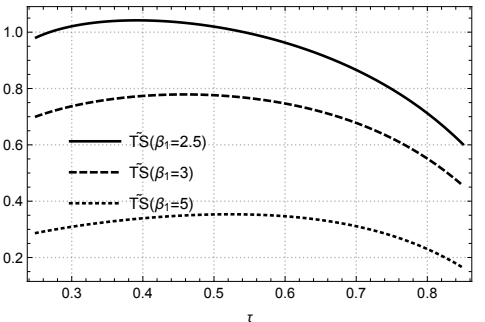

(b) $s_{0}$ neutralizes $\tau$

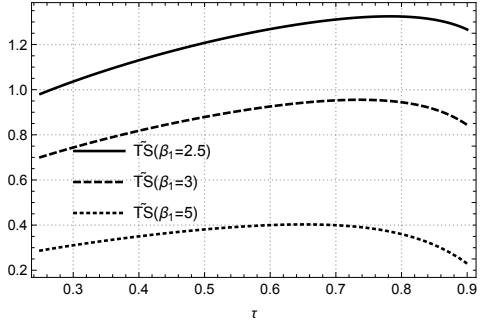

(c) $s_{1}$ neutralizes $\tau$ $X=0.01, r=0.04, \alpha=0.02, \gamma=0.5, k_{0}=1, k_{1}=0.1, s_{0}=0, s_{1}=0, \tau=0.25, \lambda=0.2$.

Figure 4: Effects of a neutral tax rate $\tau$ on welfare under different uncertainty levels 


\section{Linear demand function}

The robustness of our main results is checked replacing the iso-elastic demand function by a linear demand function (also used by Huisman and Kort (2015) and Boonman and Hagspiel (2013):

$$
P(t)=X(t)(1-\eta Q)
$$

where $\eta>0$.

Proposition 4. A firm with a proprietary option to invest in a project facing an inverse linear demand function $P=X(1-\eta Q)$, that requires a net investment of $\left(k_{1}-s_{1}\right) Q$, will optimally invest when $X$ reaches the following threshold:

$$
X_{l}^{*}=\frac{\beta_{1}+1}{\beta_{1}-1} \frac{r-\alpha}{1-\tau} \frac{r+\lambda(1-\tau)}{r+\lambda}\left(k_{1}-s_{1}\right)
$$

and choose capacity

$$
Q_{l}^{*}=\frac{1}{\eta\left(\beta_{1}+1\right)}
$$

The effects of the tax-subsidy package components are neutral in terms of the amount of investment $\left(\partial Q_{l}^{*} / \partial \tau=\partial Q_{l}^{*} / \partial \lambda=\partial Q_{l}^{*} / \partial s_{1}=0\right)$. The latter effect differs from that observed in the case of a iso-elastic demand function, for which a higher subsidy reduces the size of investment. The difference is related with the presence of a fixed investment cost.

The effects on the investment timing are obtained differentiating $X_{l}^{*}$ with respect to the fiscal policy package components:

$$
\begin{aligned}
\frac{\partial X_{l}^{*}}{\partial \tau} & =\frac{\beta_{1}+1}{\beta_{1}-1} \frac{r-\alpha}{(1-\tau)^{2}} \frac{r}{r+\lambda}\left(k_{1}-s_{1}\right)>0 \\
\frac{\partial X_{l}^{*}}{\partial \lambda} & =-\frac{\beta_{1}+1}{\beta_{1}-1} \frac{r-\alpha}{1-\tau} \frac{r \tau}{(r+\lambda)^{2}}\left(k_{1}-s_{1}\right)<0 \\
\frac{\partial X_{l}^{*}}{\partial s_{1}} & =-\frac{X_{l}^{*}}{k_{1}-s_{1}}<0,
\end{aligned}
$$

and they have the same sign those in the iso-elastic case. 
The signs of the effects of uncertainty on investment timing and scale are also identical:

$$
\begin{aligned}
& \frac{\partial X_{l}^{*}}{\partial \beta_{1}}=-\frac{2 X^{*}}{\left(\beta_{1}-1\right)\left(\beta_{1}+1\right)}<0 \\
& \frac{\partial Q_{l}^{*}}{\partial \beta_{1}}=-\frac{1}{\eta\left(\beta_{1}-1\right)^{2}}<0
\end{aligned}
$$

Table 3 summarize all the previous results and compare them with those obtained for the iso-elastic demand function. Excluding the effects of the variable subsidy to investment $\left(s_{1}\right)$, the effects of the fiscal policy instruments for the unrestricted package remain the same in both types of demand functions.

Table 3: Summary of comparative statics for linear and iso-elastic demand functions

\begin{tabular}{ccccccc}
\hline & \multicolumn{2}{c}{ Linear } & & \multicolumn{2}{c}{ Iso-elastic } \\
\cline { 2 - 3 } \cline { 5 - 6 } & $\partial X_{l}^{*}$ & $\partial Q_{l}^{*}$ & & $\partial X^{*}$ & $\partial Q^{*}$ \\
\hline$\partial \tau$ & + & 0 & & + & 0 \\
$\partial \lambda$ & - & 0 & & - & 0 \\
$\partial s_{1}$ & - & 0 & & - & + \\
\hline$\partial \sigma$ & + & + & & + & + \\
\hline
\end{tabular}

Following similar steps for analyzing the effect of each available instrument on the neutral packages (both zero-cost and zero-incremental-cost), it is possible to obtain the results presented in Table 4. As for the unrestricted case, only the variable subsidy to investment has a different impact when considering the linear inverse demand function. In fact, the positive and the ambiguous effects on investment scale, respectively for the zero-cost and zero-incremental-cost, disappear under the linear demand function, as a result of the null direct impact of $s_{1}$ on $Q_{l}^{*}$.

Table 4: Summary of results: neutral tax-subsidy package for linear and iso-elastic demand

\begin{tabular}{|c|c|c|c|c|c|}
\hline & \multirow[t]{2}{*}{ Unrestricted } & \multicolumn{2}{|c|}{ Neutral total cost } & \multicolumn{2}{|c|}{ Neutral incremental cost } \\
\hline & & $\lambda$ & $s_{1}$ & $\lambda$ & $s_{1}$ \\
\hline \multicolumn{6}{|l|}{ Linear } \\
\hline$d X^{*} / d \tau$ & + & - & \pm & \pm & \pm \\
\hline$d Q^{*} / d \tau$ & 0 & 0 & 0 & 0 & 0 \\
\hline \multicolumn{6}{|l|}{ Iso-elastic } \\
\hline$d X^{*} / d \tau$ & + & - & \pm & \pm & \pm \\
\hline$d Q^{*} / d \tau$ & 0 & 0 & + & 0 & \pm \\
\hline
\end{tabular}
functions 


\section{Conclusion}

We develop a real options model which examines the effect of subsidy and taxation policies on the timing and size of investments. We show that a higher depreciation rate, or a higher subsidy, or a lower tax rate, accelerates investments. We identify however a very important difference between the use of a fixed and a variable subsidy, whilst the former subsidy induces investments of a smaller size, the latter encourages investments of a larger size. We also conclude that both the tax rate and the assets depreciation rate do not affect the size of investments.

Considering government financial constraints, we introduce two neutral packages: the zerocost and the zero-incremental-cost packages. Under neutral packages, the clear relation that appears in the unrestricted case no longer exists. In fact, a tax rate increase, if used to compensate a higher depreciation rate or higher subsidies, may hasten or deter the investment, depending on the tax rate that is initially in place. Although the direct effect of an increase in the tax rate is to deter investment, we show that it can hasten investment if the tax revenue that is generated by the tax rate increase is used to rise the depreciation rate or to grant a subsidy. Additionally, if governments want to promote investments of a larger scale, using a zero-cost package, they should use the additional tax revenue to grant a variable subsidy. For a zero-incremental-cost package, this is also possible but for some particular parameter values only.

A welfare analysis reveals that the zero-incremental-cost package tends to be a more effective neutral package in magnifying the investment total surplus. Moreover, governments can also implement a welfare-maximizing policy by choosing the appropriate tax rate to be changed and the instrument to be adjusted to neutralize the effect of the tax rate change.

Some of the above findings are new to the literature and reveal important features of investment incentive packages that combine different types of taxes and subsidies, and can have relevant implications on the development of new public policies to encourage investment. To our best knowledge, there are not yet available empirical studies that fully test our theoretical findings, perhaps because our theory applies to public incentives that comprise both taxes and subsidies with each of these instruments comprising two instruments, corporate and assets depreciation taxes, and fixed and variable subsidies, respectively, and are evaluated under a neutral incentive package and market uncertainty. 
Among the limitations of our study, we neglect possible efficiency losses in collecting taxes and distributing subsidies, as well as any inter-temporal preferences and government constraints. We let the overcoming of these limitations as further research. 


\section{References}

Abrell, J., Rausch, S., and Streitberger, C. (2019). The economics of renewable energy support. Journal of Public Economics, 176:94-117.

Adkins, R. and Paxson, D. (2013). The effect of tax depreciation on the stochastic replacement policy. European Journal of Operational Research, 229(1):155-164.

Agliardi, E. (2001). Taxation and investment decisions: a real options approach. Australian Economic Papers, 40(1):44-55.

Alvarez, L. H. and Koskela, E. (2008). Progressive taxation, tax exemption, and irreversible investment under uncertainty. Journal of Public Economic Theory, 10(1):149-169.

Bar-Ilan, A. and Strange, W. C. (1999). The timing and intensity of investment. Journal of Macroeconomics, 21(1):57-77.

Becker, B. (2015). Public r\&d policies and private r\&d investment: A survey of the empirical evidence. Journal of Economic Surveys, 29(5):917-942.

Bjorvatn, K. and Eckel, C. (2006). Policy competition for foreign direct investment between asymmetric countries. European Economic Review, 50(7):1891-1907.

Boonman, H. and Hagspiel, V. (2013). Sensitivity of demand function choice in a strategic real options context.

Busom, I. (2000). An empirical evaluation of the effects of r\&d subsidies. Economics of innovation and new technology, 9(2):111-148.

Dangl, T. (1999). Investment and capacity choice under uncertain demand. European Journal of Operational Research, 117(3):415-428.

Danielova, A. and Sarkar, S. (2011). The effect of leverage on the tax-cut versus investmentsubsidy argument. Review of Financial Economics, 20(4):123-129.

David, P. A., Hall, B. H., and Toole, A. A. (2000). Is public r\&d a complement or substitute for private r\&d? a review of the econometric evidence. Research policy, 29(4-5):497-529. 
Dimos, C. and Pugh, G. (2016). The effectiveness of r\&d subsidies: A meta-regression analysis of the evaluation literature. Research Policy, 45(4):797-815.

Dixit, A. and Pindyck, R. (1994). Investment Under Uncertainty. Princeton University Press, New Jersey.

Djankov, S., Ganser, T., McLiesh, C., Ramalho, R., and Shleifer, A. (2010). The effect of corporate taxes on investment and entrepreneurship. American Economic Journal: Macroeconomics, 2(3):31-64.

Fuest, C. and Huber, B. (2000). Why do governments subsidise investment and not employment? Journal of Public Economics, 78(1-2):171-192.

Görg, H. and Strobl, E. (2007). The effect of r\&d subsidies on private r\&d. Economica, $74(294): 215-234$.

Gries, T., Prior, U., and Sureth, C. (2012). A tax paradox for investment decisions under uncertainty. Journal of Public Economic Theory, 14(3):521-545.

Guellec, D. and Van Pottelsberghe De La Potterie, B. (2003). The impact of public r\&d expenditure on business r\&d. Economics of innovation and new technology, 12(3):225-243.

Hansson, I. and Stuart, C. (1989). Why is investment subsidized? International Economic Review, pages 549-559.

Hassett, K. A. and Hubbard, R. G. (2002). Tax policy and business investment. In Handbook of public economics, volume 3, pages 1293-1343. Elsevier.

Haufler, A. and Wooton, I. (1999). Country size and tax competition for foreign direct investment. Journal of Public Economics, 71(1):121-139.

House, C. L. and Shapiro, M. D. (2008). Temporary investment tax incentives: Theory with evidence from bonus depreciation. American Economic Review, 98(3):737-68.

Huang, W., Zhou, W., Chen, J., and Chen, X. (2019). The governments optimal subsidy scheme under manufacturers competition of price and product energy efficiency. Omega, 84:70-101.

Huberts, N. F., Huisman, K. J., Kort, P. M., and Lavrutich, M. N. (2015). Capacity choice in (strategic) real options models: A survey. Dynamic Games and Applications, 5(4):424-439. 
Huisman, K. J. and Kort, P. M. (2015). Strategic capacity investment under uncertainty. The RAND Journal of Economics, 46(2):376-408.

Jorgenson, D. W. (1963). Capital theory and investment behavior. The American Economic Review, 53(2):247-259.

Judd, K. L. (1997). The optimal tax rate for capital income is negative. Technical report, National Bureau of Economic Research.

Klemm, A. (2010). Causes, benefits, and risks of business tax incentives. International Tax and Public Finance, 17(3):315-336.

Klemm, A. and Van Parys, S. (2012). Empirical evidence on the effects of tax incentives. International Tax and Public Finance, 19(3):393-423.

Ohrn, E. (2018). The effect of corporate taxation on investment and financial policy: evidence from the dpad. American Economic Journal: Economic Policy, 10(2):272-301.

Pennings, E. (2000). Taxes and stimuli of investment under uncertainty. European Economic Review, 44(2):383-391.

Pennings, E. (2005). How to maximize domestic benefits from foreign investments: the effect of irreversibility and uncertainty. Journal of Economic Dynamics and Control, 29(5):873-889.

Rotemberg, M. (2019). Equilibrium effects of firm subsidies. American Economic Review, 109(10):3475-3513.

Sarkar, S. (2012). Attracting private investment: Tax reduction, investment subsidy, or both? Economic Modelling, 29(5):1780-1785.

Sarkar, S. (2020). The uncertainty-investment relationship with endogenous capacity. Omega.

Sorbe, S. and Johansson, Å. (2017). International tax planning and fixed investment.

Straub, L. and Werning, I. (2020). Positive long-run capital taxation: Chamley-judd revisited. American Economic Review, 110(1):86-119.

Sureth, C. (2002). Partially irreversible investment decisions and taxation under uncertainty: a real option approach. German Economic Review, 3(2):185-221. 
Tian, Y. (2018). Optimal policy for attracting FDI: Investment cost subsidy versus tax rate reduction. International Review of Economics \& Finance, 53:151-159.

Wong, K. P. (2012). Taxes, leverage, and stimuli of investment under uncertainty. Annual International Conference on Real Options, 2012.

Yang, Y.-c., Nie, P.-y., Liu, H.-t., and Shen, M.-h. (2018). On the welfare effects of subsidy game for renewable energy investment: toward a dynamic equilibrium model. Renewable Energy, 121:420-428.

Yu, C.-F., Chang, T.-C., and Fan, C.-P. (2007). FDI timing: Entry cost subsidy versus tax rate reduction. Economic Modelling, 24(2):262-271.

Zee, H. H., Stotsky, J. G., and Ley, E. (2002). Tax incentives for business investment: a primer for policy makers in developing countries. World development, 30(9):1497-1516. 


\section{A Proofs of propositions}

Proof. Proof of Proposition 1

The firm profit is given by:

$$
\pi(t)=Q P(t)(1-\tau)+\lambda\left(k_{0}+k_{1} Q\right) e^{-\lambda(t-T)} \tau
$$

The expected present value at the investment moment, when $X(T)=X$ is:

$$
\begin{aligned}
V(X, Q)= & E\left[\int_{t=T}^{\infty}\left(Q X(t) Q^{-\gamma}(1-\tau)+\lambda\left(k_{0}+k_{1} Q\right) e^{-\lambda(t-T)} \tau\right) e^{-r t} d t\right. \\
& \left.-\left(k_{0}+k_{1} Q\right) e^{-r T}\right] \\
= & \frac{X Q^{1-\gamma}}{r-\alpha}(1-\tau)-\left(k_{0}+k_{1} Q\right) \frac{r+\lambda(1-\tau)}{r+\lambda}
\end{aligned}
$$

Maximizing with respect to $Q$, using the first order condition:

$$
\frac{(1-\gamma) X Q^{-\gamma}}{r-\alpha}(1-\tau)-k_{1} \frac{r+\lambda(1-\tau)}{r+\lambda}=0
$$

leads to:

$$
Q^{*}(X)=\left(\frac{(1-\gamma)(1-\tau) X}{(r-\alpha) k_{1}} \frac{r+\lambda}{r+\lambda(1-\tau)}\right)^{\frac{1}{\gamma}}
$$

Substituting in Equation (44) and simplifying:

$$
V\left(X, Q^{*}(X)\right)=\left(\frac{\gamma}{1-\gamma} k_{1}\left(\frac{(1-\gamma)(1-\tau) X}{(r-\alpha) k_{1}} \frac{r+\lambda}{r+\lambda(1-\tau)}\right)^{\frac{1}{\gamma}}-k_{0}\right) \frac{r+\lambda(1-\tau)}{r+\lambda}
$$

Using standard real options procedures (Dixit and Pindyck, 1994), $X^{*}$ is found with the following value-matching and smooth-pasting conditions:

$$
\begin{aligned}
A X^{* \beta_{1}} & =\left(\frac{\gamma}{1-\gamma} k_{1}\left(\frac{(1-\gamma)(1-\tau) X^{*}}{(r-\alpha) k_{1}} \frac{r+\lambda}{r+\lambda(1-\tau)}\right)^{\frac{1}{\gamma}}-k_{0}\right) \frac{r+\lambda(1-\tau)}{r+\lambda} \\
\beta_{1} A X^{* \beta_{1}-1} & =\left(\frac{1}{1-\gamma} k_{1} X^{* \frac{1}{\gamma}-1}\left(\frac{(1-\gamma)(1-\tau)}{(r-\alpha) k_{1}} \frac{r+\lambda}{r+\lambda(1-\tau)}\right)^{\frac{1}{\gamma}}\right) \frac{r+\lambda(1-\tau)}{r+\lambda}
\end{aligned}
$$


These two conditions are equivalent to Equation (6) and produce the following solution:

$$
X^{*}=\left(\frac{\beta_{1}(1-\gamma) k_{0}}{\left(\beta_{1} \gamma-1\right) k_{1}}\right)^{\gamma} \frac{r-\alpha}{(1-\gamma)(1-\tau)} \frac{r+\lambda(1-\tau)}{r+\lambda} k_{1}
$$

Replacing in Equation (46):

$$
Q^{*} \equiv Q^{*}\left(X^{*}\right)=\frac{\beta_{1}(1-\gamma) k_{0}}{\left(\beta_{1} \gamma-1\right) k_{1}}
$$

Proof. Proof of Propositions 2 and 3

Noting that

$$
\begin{aligned}
X^{*} & =\left(\frac{\beta_{1}(1-\gamma)\left(k_{0}-s_{0}\right)}{\left(\beta_{1} \gamma-1\right)\left(k_{1}-s_{1}\right.}\right)^{\gamma} \frac{r-\alpha}{(1-\gamma)(1-\tau)} \frac{r+\lambda(1-\tau)}{r+\lambda}\left(k_{1}-s_{1}\right) \\
& =Q^{* \gamma} \frac{r-\alpha}{(1-\gamma)(1-\tau)} \frac{r+\lambda(1-\tau)}{r+\lambda}\left(k_{1}-s_{1}\right)
\end{aligned}
$$

Equation (21) simplifies to:

$$
\begin{aligned}
R\left(X, \tau, \lambda, s_{0}, s_{1}\right)= & \left(\left(\left(\frac{r+\lambda(1-\tau)}{(1-\gamma)(1-\tau)(r+\lambda)}-\frac{\lambda}{r+\lambda}\right)\left(k_{1}-s_{1}\right) \tau-s_{1}\right) Q^{*}\right. \\
& \left.\quad-\frac{\lambda}{r+\lambda}\left(k_{0}-s_{0}\right) \tau-s_{0}\right)\left(\frac{X}{X^{*}}\right)^{\beta_{1}} \\
= & g\left(\frac{X}{X^{*}}\right)^{\beta_{1}}
\end{aligned}
$$

Differentiating Equation (54) allows us to find the partial derivative of one the package components when another adjusts to neutralize the effect:

$$
\frac{\partial R}{\partial i}+\frac{\partial R}{\partial j} \frac{\partial j}{\partial i}=0, \quad i \neq j \in\left\{\tau, \lambda, s_{0}, s_{1}\right\}
$$

All derivatives are evaluated at $\left(\hat{\tau}, \hat{\lambda}, \hat{s_{0}}, \hat{s_{1}}\right)$.

Noting that

$$
\frac{\partial R}{\partial i}=\left(\frac{\partial g}{\partial i}-\beta_{1} g \frac{\partial X^{*}}{\partial i} X^{*-1}\right)\left(\frac{X}{X^{*}}\right)^{\beta_{1}}, \quad i \in\left\{\tau, \lambda, s_{0}, s_{1}\right\}
$$


Equation (55) can be presented as:

$$
\frac{\partial j}{\partial i}=-\frac{\frac{\partial R}{\partial i}}{\frac{\partial R}{\partial j}}=-\frac{\frac{\partial g}{\partial i}-\beta_{1} g \frac{\partial X^{*}}{\partial i} X^{*-1}}{\frac{\partial g}{\partial j}-\beta_{1} g \frac{\partial X^{*}}{\partial j} X^{*-1}}, \quad i \neq j \in\left\{\tau, \lambda, s_{0}, s_{1}\right\}
$$

1. Let us first analyze the case of a zero total cost package $(g=0)$, as in Proposition 2 .

Using the proofs below it is possible to show that:

$$
\frac{\partial \hat{\lambda}}{\partial \hat{\tau}}=-\frac{\frac{\partial R}{\partial \hat{\tau}}}{\frac{\partial R}{\partial \hat{\lambda}}}>0 ; \quad \frac{\partial \hat{s_{0}}}{\partial \hat{\tau}}=-\frac{\frac{\partial R}{\partial \hat{\tau}}}{\frac{\partial R}{\partial \hat{s_{0}}}}>0 ; \quad \frac{\partial \hat{s_{1}}}{\partial \hat{\tau}}=-\frac{\frac{\partial R}{\partial \hat{\tau}}}{\frac{\partial R}{\partial \hat{s_{1}}}}>0
$$

i. Noting that $r>0, r-\alpha>0,0<\gamma<1, \hat{\lambda} \geqslant 0, \hat{\tau} \geqslant 0, k_{1}-\hat{s_{1}} \geqslant 0, k_{0}-\hat{s_{0}} \geqslant 0$, $\partial Q^{*} / \partial \tau=0$

$$
\frac{\partial R}{\partial \tau}=\left(\frac{r+\hat{\lambda}(1-\hat{\tau})^{2}}{(1-\gamma)(1-\hat{\tau})^{2}(r+\hat{\lambda})}-\frac{\hat{\lambda}}{r+\hat{\lambda}}\right)\left(k_{1}-\hat{s_{1}}\right) \hat{Q}^{*}-\frac{\hat{\lambda}}{r+\hat{\lambda}}\left(k_{0}-\hat{s_{0}}\right)
$$

Please notice that for a zero-cost package $\left(R\left(X, \hat{\tau}, \hat{\lambda}, \hat{s_{0}}, \hat{s_{1}}\right)=0\right)$, from Equation (54):

$$
\begin{array}{r}
-\frac{\hat{\lambda}}{r+\hat{\lambda}}\left(k_{1}-\hat{s_{1}}\right) \hat{Q^{*}}-\frac{\hat{\lambda}}{r+\hat{\lambda}}\left(k_{0}-\hat{s_{0}}\right)=-\frac{r+\hat{\lambda}(1-\hat{\tau})}{(1-\gamma)(1-\hat{\tau})(r+\hat{\lambda})}\left(k_{1}-\hat{s_{1}}\right) \hat{Q}^{*} \\
+\frac{\hat{s_{0}}+\hat{s_{1}} \hat{Q}^{*}}{\hat{\tau}}
\end{array}
$$

and that

$$
\frac{r+\hat{\lambda}(1-\hat{\tau})^{2}}{(1-\gamma)(1-\hat{\tau})^{2}(r+\hat{\lambda})}>\frac{r+\hat{\lambda}(1-\hat{\tau})}{(1-\gamma)(1-\hat{\tau})(r+\hat{\lambda})}
$$

Therefore, $\frac{\partial R}{\partial \tau}>0$.

ii. Noting additionally that $\partial Q^{*} / \partial \lambda=0$,

$$
\frac{\partial R}{\partial \lambda}=\left(-\frac{r \hat{\tau}}{(1-\gamma)(1-\hat{\tau})(r+\hat{\lambda})^{2}}-\frac{r}{(r+\hat{\lambda})^{2}}\right)\left(k_{1}-\hat{s_{1}}\right) \hat{\tau} \hat{Q}^{*}-\frac{r}{(r+\hat{\lambda})^{2}}\left(k_{0}-\hat{s_{0}}\right) \hat{\tau}<0
$$


iii. Noting additionally that $\partial Q^{*} / \partial s_{0}<0$,

$$
\frac{\partial R}{\partial s_{0}}=\left(\left(\frac{r+\hat{\lambda}(1-\hat{\tau})}{(1-\gamma)(1-\hat{\tau})(r+\hat{\lambda})}-\frac{\hat{\lambda}}{r+\hat{\lambda}}\right)\left(k_{1}-\hat{s_{1}}\right) \hat{\tau}-\hat{s_{1}}\right) \frac{\partial Q^{*}}{\partial s_{0}}-\frac{r+\hat{\lambda}(1-\hat{\tau})}{r+\hat{\lambda}}
$$

Please notice that for a zero-cost package $\left(R\left(X, \hat{\tau}, \hat{\lambda}, \hat{s_{0}}, \hat{s_{1}}\right)=0\right)$, from Equation (54):

$$
\left(\frac{r+\hat{\lambda}(1-\hat{\tau})}{(1-\gamma)(1-\hat{\tau})(r+\hat{\lambda})}-\frac{\hat{\lambda}}{r+\hat{\lambda}}\right)\left(k_{1}-\hat{s_{1}}\right) \hat{\tau}-\hat{s_{1}}=\left(\frac{\lambda}{r+\lambda}\left(k_{0}-s_{0}\right) \tau+s_{0}\right){\hat{Q^{*}}}^{-1}>0
$$

Therefore, $\frac{\partial R}{\partial s_{0}}<0$.

iv. Noting additionally that $\partial Q^{*} / \partial s_{1}>0$,

$$
\begin{array}{r}
\frac{\partial R}{\partial s_{1}}=\left(\left(\frac{r+\hat{\lambda}(1-\hat{\tau})}{(1-\gamma)(1-\hat{\tau})(r+\hat{\lambda})}-\frac{\hat{\lambda}}{r+\hat{\lambda}}\right)\left(k_{1}-\hat{s_{1}}\right) \hat{\tau}-\hat{s_{1}}\right) \frac{\partial Q^{*}}{\partial s_{1}} \\
-\left(\left(\frac{r+\hat{\lambda}(1-\hat{\tau})}{(1-\gamma)(1-\hat{\tau})(r+\hat{\lambda})}-\frac{\hat{\lambda}}{r+\hat{\lambda}}\right) \hat{\tau}+1\right) \hat{Q}^{*}
\end{array}
$$

Please notice that

$$
\left(\frac{r+\hat{\lambda}(1-\hat{\tau})}{(1-\gamma)(1-\hat{\tau})(r+\hat{\lambda})}-\frac{\hat{\lambda}}{r+\hat{\lambda}}\right) \hat{\tau}+1>0
$$

Therefore, $\frac{\partial R}{\partial s_{1}}<0$.

2. For the case of a zero incremental cost package $(g>0)$, as in Proposition 3 , we need to consider the effect on the discount factor through $\frac{\partial X^{*}}{\partial i}$. From previous proofs, this derivative has always the same sign as $\frac{\partial g}{\partial i}$, which leads to the non-monotonic effects.

Proof. Proof of Proposition 4 
The expected present value of the profits at the investment moment, when $X(T)=X$ is:

$$
\begin{aligned}
V_{m}(X, Q)=E\left[\int_{t=T}^{\infty}\left(Q X(t)(1-\eta Q)(1-\tau)+\lambda\left(k_{0}-s_{0}+\left(k_{1}-s_{1}\right) Q\right) e^{-\lambda(t-T)} \tau\right) e^{-r t} d t\right. \\
\left.\quad-\left(k_{0}+k_{1} Q\right) e^{-r T}\right] \\
=\frac{Q X(1-\eta Q)}{r-\alpha}(1-\tau)-\left(k_{0}-s_{0}+\left(k_{1}-s_{1}\right) Q\right) \frac{r+\lambda(1-\tau)}{r+\lambda}
\end{aligned}
$$

Maximizing with respect to $Q$, using the first order condition:

$$
\frac{X(1-2 \eta Q)}{r-\alpha}(1-\tau)-\frac{r+\lambda(1-\tau)}{r+\lambda}\left(k_{1}-s_{1}\right)=0
$$

leads to:

$$
Q_{l}^{*}(X)=\frac{1}{2 \eta}\left(\frac{r-\alpha}{(1-\tau) X} \frac{r+\lambda(1-\tau)}{r+\lambda}\left(k_{1}-s_{1}\right)\right)
$$

Substituting in Equation (67) and using the value-matching and smooth-pasting conditions:

$$
\begin{aligned}
B X_{l}^{* \beta_{1}} & =V_{m}\left(X_{l}^{*}, Q_{l}^{*}\left(X_{l}^{*}\right)\right) \\
\beta_{1} B X_{l}^{* \beta_{1}-1} & =\left.\frac{\partial V_{m}\left(X, Q_{l}^{*}\left(X_{l}^{*}\right)\right)}{\partial X}\right|_{X=X_{l}^{*}}
\end{aligned}
$$

the following solution is obtained:

$$
\begin{aligned}
X_{l}^{*} & =\frac{\beta_{1}+1}{\beta_{1}-1} \frac{r-\alpha}{1-\tau} \frac{r+\lambda(1-\tau)}{r+\lambda}\left(k_{1}-s_{1}\right) \\
Q_{l}^{*} & =\frac{1}{\eta\left(\beta_{1}+1\right)}
\end{aligned}
$$

\section{B Proofs of corollaries}

Proof. Proof of Corollary 1

The proof is straightforward given $\beta_{1}>1, \beta_{1} \gamma>1, r-\alpha>0,0<\gamma<1,0<\tau<1, k_{0}>0$, and $k_{1}>0$.

Proof. Proof of Corollary 2

See previous proof. 
Proof. Proof of Corollary 3

Se previous proofs and note that $k_{0}-s_{0}>0$ and $k_{1}-s_{1}>0$.

Proof. Proof of Corollary 4

The only effect that is not straightforward from the signs of the individual components is the following:

$$
\frac{d \hat{X}^{*}}{d \hat{\tau}}=\underbrace{\frac{\partial \hat{X}^{*}}{\partial \hat{\tau}}}_{>0}+\underbrace{\frac{\partial \hat{X}^{*}}{\partial \hat{\lambda}}}_{<0} \underbrace{\frac{\partial \hat{\lambda}}{\partial \hat{\tau}}}_{>0}<0
$$

Please notice that from Equations (10) and (12):

$$
\frac{\partial \hat{X}^{*}}{\partial \hat{\lambda}}=\frac{\partial \hat{X}^{*}}{\partial \hat{\tau}} \frac{\hat{\tau}(1-\hat{\tau})}{r+\hat{\lambda}}
$$

Substituting in Equation (74), the condition becomes:

$$
\frac{\partial \hat{\lambda}}{\partial \hat{\tau}}<\frac{r+\hat{\lambda}}{\hat{\tau}(1-\hat{\tau})}
$$

Notice that for a neutral package:

$$
\begin{aligned}
\frac{\partial R}{\partial \hat{\tau}}+\frac{\partial R}{\partial \hat{\lambda}} \frac{\partial \hat{\lambda}}{\partial \hat{\tau}} & =0 \\
\frac{\partial \hat{\lambda}}{\partial \hat{\tau}} & =-\frac{\frac{\partial R}{\partial \hat{\tau}}}{\frac{\partial R}{\partial \hat{\lambda}}}
\end{aligned}
$$

From Equations (58) and (61) it is possible to show that:

$$
\frac{\partial R}{\partial \hat{\lambda}}=-\frac{\hat{\tau}(1-\hat{\tau})}{r+\hat{\lambda}}\left(\frac{\partial R}{\partial \hat{\tau}}+a\right)
$$

where

$$
a=\left(\frac{r \hat{\tau}-\left(r+\hat{\lambda}(1-\hat{\tau})^{2}\right)}{(1-\gamma)(1-\hat{\tau})^{2}(r+\hat{\lambda})}\right)\left(k_{1}-\hat{s_{1}}\right) \hat{Q}^{*}+\left(k_{1}-\hat{s_{1}}\right) \hat{Q}^{*}+\left(k_{0}-\hat{s_{0}}\right)
$$


and therefore:

$$
\frac{\partial \hat{\lambda}}{\partial \hat{\tau}}=\frac{\frac{\partial R}{\partial \hat{\tau}}}{\frac{\partial R}{\partial \hat{\tau}}+a} \times \frac{r+\hat{\lambda}}{\hat{\tau}(1-\hat{\tau})}>\frac{r+\hat{\lambda}}{\hat{\tau}(1-\hat{\tau})}
$$

This condition is equivalent to $a>0$, or:

$$
b=r \hat{\tau}-\left(r+\hat{\lambda}(1-\hat{\tau})^{2}\right)>0
$$

In order to prove this condition to be true, noticing that for $\hat{\tau}=0, b=-(r+\hat{\lambda})<0$, we need only to prove that $b$ is decreasing, i.e. $d b / d \hat{\tau}<0$. For $r<1$ and noting that $r>0, \hat{\lambda} \geqslant 0$, $\hat{\tau} \geqslant 0$, and $\partial \hat{\lambda} / \partial \hat{\tau}>0$ :

$$
\frac{d b}{d \hat{\tau}}=r-1-\left((1-\hat{\tau})^{2} \frac{\partial \hat{\lambda}}{\partial \hat{\tau}}+2(1-\hat{\tau}) \hat{\lambda}\right)<0
$$

